\title{
Assessing and Monitoring of the Main Contributors to the Declining Food Production and Food Security, Case Study Kieni-Sub County: Kenya
}

\author{
Kibungà Eunice Wanjiru*, Thomas. G. Ngigi \\ Department of Geomatic Engineering and Geospatial Information Systems, Jomo Kenyatta University of Science and Technology, \\ Nairobi, Kenya \\ *Corresponding author: ekibunga46@gmail.com
}

\begin{abstract}
Kenya, like most parts of the world, is experiencing low food production which is leading to food Insecurity. This has a great significance in the livelihoods of the locals due to low food production and insecurity. An analysis of trends in rainfall patterns, extreme and or slow onset events, crop failure, health and crop vigor throughout the growing period, reduced food production units in the farms, points to clear evidence of some of the key contributors to low and reduced food production in many areas. The purpose of the study is to assess and monitor the key contributors to reduced/low food production in the area of study through the classification of land use land cover of the area to analyze the area extent of farm lands or cropped areas over time and determine the shift in usage, Vegetation health and vigor of the study area over time ,the impacts of the rainfall factors on food production by; estimating the annual rainfall amounts, distribution and trends over a period of time, Crop yields over a continuous period of time. Landsat satellite images were used for the years 2000, 2005, 2010 and 2015 for Land cover Land use classification and NDVI, rainfall data used was CHIPRS analyzed using GeoClim and food production data from Harvest Choice analyzed in excel. This study determined that indeed the area of study has recorded reduced food production, a lot of conversions from land use initially on food crops to other uses, change and decreased rainfall as the main contributors to the problem.
\end{abstract}

Keywords: land cover land use, food production, vegetation index, satellite imagery and data

Cite This Article: Kibungà Eunice Wanjiru, and Thomas. G. Ngigi, “Assessing and Monitoring of the Main Contributors to the Declining Food Production and Food Security, Case Study Kieni-Sub County: Kenya.” Journal of Food Security, vol. 5, no. 3 (2017): 88-99. doi: 10.12691/jfs-5-3-4.

\section{Introduction}

Agriculture is by far the single most important economic activity in Sub-Saharan Africa. It provides employment for about two-thirds of the continent's working population and for each country contributes an average of 30 to 60 percent of gross domestic product and about 30 percent of the value of exports. Since the 1960s, the rate of agricultural output has lagged behind the rate of population growth. Between 1965 and 1990, agricultural production grew at an annual rate of 1.7 percent, over onethird less than the 2.8 percent average annual population growth rate. In the late 1970 s, for the first time in history, sub-Saharan Africa became a net importer of food [3]. The agricultural sector's growth has lagged behind national economic growth in Africa, according to an International Food Policy Research Institute study [10]. Given that most poor people are dependent on farming, this slow growth is an obstacle to regional poverty reduction, the study finds, and African policymakers should include an emphasis on agricultural growth [3].

The major agricultural crops in Africa are: all the principal grains corn, wheat, and rice in that order of importance. Corn has the widest distribution, being grown in virtually all ecological zones. In Kenya they are grown at the highland zones of the country. Cultivation of the hardy cassava has expanded tremendously, particularly in western and central Africa; it has displaced the cultivation of yams in many areas and has ceased to be regarded as just famine reserve. Potatoes are cultivated in the higher elevations of such countries as Ethiopia, Kenya, and Madagascar, as well as in areas of Mediterranean climates in North and South Africa. Sweet potatoes have a more tropical and subtropical distribution, while the plantain is grown extensively in the tropical forest zones.

The agricultural sector is the mainstay of the Kenya's economy. The sector directly contributes $24 \%$ of the Gross Domestic Product (GDP) and 27\% of GDP indirectly through linkages with manufacturing, distribution and other service related sectors. In the recent years, the country has been facing low agricultural food production problems. This significantly leads to food insecurity [12]. These are attributed to many factor several factors including change of crop type from food production crop type to other productions on the farms units especially to Horticultural produces.

With the horticulture farming practice becoming so vibrant in the developing countries to cater in to the 
demand in the developed world, this is compromising the food production in the developing countries [15].

The horticulture industry especially in Kieni Sub County is the fastest growing agricultural sub-sector in the sub county, and is ranked high in terms of foreign exchange earnings from exports. Many farmers have completely abandoned the food production sector and enhanced the horticultural production. This has significantly led to the decline in food production and complete abandonment of the same.

Climatic factors variability and change currently place significant stresses on food production and availability. Global climate change is expected to increase over the next century. Human-induced global warming is likely to cause increased risk of hunger and famine, especially amongst the world's poor. Improved adaptation of food production, particularly to current climate variability, which is large, holds the key to improving food security for the global population. Climate change is a change in the statistical distribution of weather patterns when that change lasts for an extended period of time. With many facets of food security directly depending on environmental conditions, then the instability of the same does have a significant impact on food production [4].

Kieni Sub County was once a very productive area in terms of food cropping, but in recent years this has changed prompting the area to rely on relief food even when the horticultural side of it seems to flourish, or at least in some of the county`s areas. So then this begs the question, WHY?

This study then aims at answering the question WHY? Through the establishment of the current land use against the past in terms extents, has it reduced? If yes to what other land use, if no, what has replaced the 'original' cropping's in the area. What contribution do the varying climatic factors have to the declining state of food production? The main threats to food production decline in Kieni Sub County are the land use conversions to other uses, climatic variability and in other cases exploitation of the soils to appoint they can never perform as before.

The significance of the study is that it will establish the problem and the results can be used in support of decision making in terms of securing the food status in the county, and really look at the cons and pros of Horticulture farming and the ways to fix the gap that it causes in terms of food security.

\section{Methodology, Data Processing and Analysis}

\subsection{Study Area}

Kieni Sub-County can generally be classified as an area of high agro ecological potential due to the slopes of $\mathrm{Mt}$ Kenya and the abundant rivers, especially Kabaru area which is a high producer of food and horticulture, Narumoru, Warazo jet, Munyu and Karicheni. There are various economic activities that drive the economy of Kieni Sub-County. The main food crops grown in the county are maize, beans, Irish potatoes, vegetables and horticulture like cut flowers. Tea and Coffee are grown in the upper zone next to Aberdare's and the Mt. Kenya forest while coffee is grown in the lower region. Cut flowers are mainly grown in Kieni East where there are large land holding sizes.
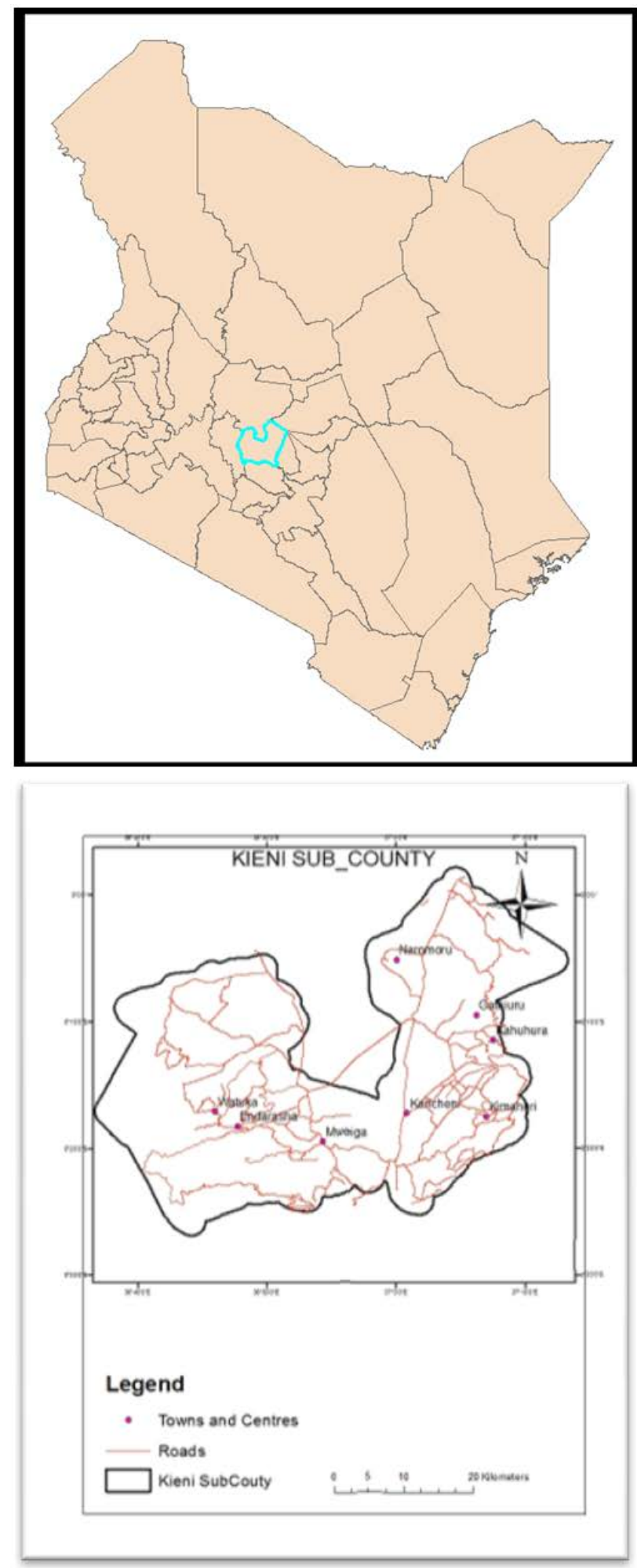

Figure 1. The study area

\subsection{Climate of the Study Area}

Kieni Sub-county in Nyeri county has some of the lowest temperatures in Kenya which range between $12^{\circ} \mathrm{C}$ in the cold months (June and July) and $27^{\circ} \mathrm{C}$ in the hot months (January-March and September-October) with high precipitation all year round. The rainfall average lies 
between $500 \mathrm{~mm}$ and $1500 \mathrm{~mm}$ during the short and long rains periods making it conducive for its diverse agricultural activity. The area is classified as Cbf by Koppen and Geiger with average temperatures of 17.1 Celsius.

\subsection{Data Sources and Requirements}

For data collection, the data sources include satellite imagery acquisition, preprocessing, interpretation and analysis. Ancillary data from reliable relevant sources was used to help in the confirmations. Datasets used include Landsat Imagery for the study years for Land Use Land Cover Classification, Normalized Difference Vegetation Index (NDVI), Chirps Data on Rainfall and Precipitation, Yields data from harvest choice.

Table 1. showing the datasets and source

\begin{tabular}{|c|c|c|}
\hline Data & Data Type & Access \\
\hline RAINFALL & CHIRPS & Geoclim \\
\hline LAND USE LAND COVER & LANDSAT TM & Usgs \\
\hline NDVI & LANDSAT TM & Usgs \\
\hline $\begin{array}{c}\text { YIELSDS/PRODUCTION } \\
\text { DATA }\end{array}$ & SATELLITE DATA & $\begin{array}{c}\text { Harvest } \\
\text { choice }\end{array}$ \\
\hline
\end{tabular}

\subsection{Data Preparation and Preprocessing}

This project mainly used Satellite Data for the analysis and research. . Datasets used include Landsat Imagery for the study years for Land Use Land Cover Classification, Normalized Difference Vegetation Index (NDVI). The Landsat imagery covering the study area in path and row isYear_P168_R060.

Image selection for the study epochs in relation to; Cloud Cover, Zero cloud cover is desired but the study area being a mountainous area it's an uphill task to get one with no clouds. Low cloud cover (20\%) was acceptable for the study if there are large cloud free areas within a scene and cloud was masked out; The dry Season 'windows' were used that were between July to August.

After cloud masking, the images are layer stacked, clipping is done to remove the pixels noises along the edges of the images and subset using the study area shapefile. (Figure 2).

\subsection{Radio-metric Correction}

Radio-metric correction refers to a set of techniques that are applied during remote sensing data processing and includes corrections related to the sensitivity of the remote sensor, topography and sun angle, and atmospheric scattering and absorption. This was done on the raw images to take care of the errors from sensor defects, scan angle variation. This involves the conversion of the Digital Numbers values (ranges from 0-255) to spectral radiance at the sensor, Conversion of the spectral radiance to apparent reflectance and the atmospheric correction.

\subsection{Atmospheric Correction}

Atmospheric correction was done on the radio metrically corrected images to remove the effects of the atmosphere on the reflectance values of images taken by satellite or airborne sensors mainly aerosols and water vapor.

\subsection{Terrain Illumination Correction (TIC)}

The images of the study area had variations in slope and aspect of the land which affects the amount of incident and light from the surface. This effects the image as in the extreme areas of the sloppy areas around Kabaru and Warazo areas some areas reflected as true shadow hence affecting the true classification of the areas. Hence the Terrain Illumination Correction to have a uniform digital signal in the image in areas overshadowed to the same as the other well light areas. This is typically shadow removal that is cast by the trees canopy. To avoid removal of the real shadows, a woody mask is first developed in order to avoid those areas during the illumination process.

\subsection{Land Use Land Cover Classification}

To get the study area's agricultural land extent, a land cover land use classification of the area was carried out. Trend analysis on the different years of study was established to see how the agricultural area extents has been changing over time. A total of six land use land cover classes were derived namely; Forestland, Cropland, Bushland, Grassland, Waterbody and Other land.

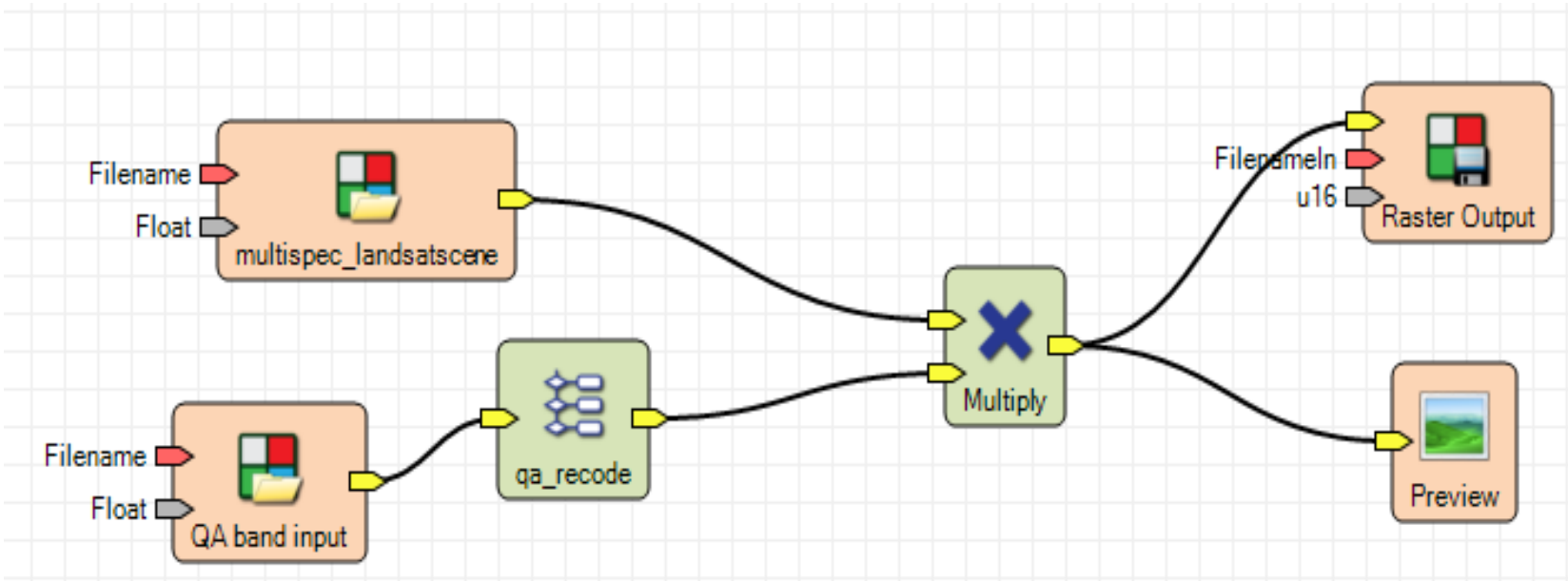

Figure 2. Cloud masking process using ERDAS IMAGINE spatial model editor 
The data used is Landsat Imagery medium resolution (30m) for the study periods using the the classification method known as random forests (RF TM) (Brieman, 2001).

The approach that was adopted in this study was to subdivide or stratify the area of study into smaller zones related to the mix of land covers, and to their spectral signals. Hence Stratification. Stratification is a technique used to divide a set of data into groups (strata) which are similar in some way.The classification is trained in ArcMap for the different classification classes targeted and applied separately for each stratification zone within the image. The method of classification used is Random Forests (RF). RF is a modern ensemble decision tree approach (Brieman, 2001), which has a number of advantages over parametric classifiers such as maximum likelihood (ML). In particular, RF provides measures of confidence for each pixel for each class, and training requirements are less rigorous than for $\mathrm{ML}$. RF is a supervised classification approach which uses selected training samples from the image which is then implemented in a program script in the statistical language ' $R$ '. The output is then loaded in ENVI for Density slicing on the output 11 band tiff images to separate the band 1 from the other probability bands \& color code the classification then mosaicking with the all the other Zones to have the Land cover Classification for the study area.

Accuracy assessment for the 2015 Land use Land cover classification was done by Randomly selecting the points and validation done on a high Resolution imagery ( Google Earth) that complimented the reference points randomly taken in the field and the Confusion Matrix run in Envi using Ground Truth Regions of Interest ( ROIs).

\subsection{Normalized Difference Vegetation Index (NDVI)}

Normalized Difference Vegetation Index (NDVI) has been used in crop health and vigor assessment. Landsat Imagery was used for this analysis, analysis done in ArcGIS using the Image Analysis window. The Red Band 3 and Infra-Red Band 4 are used with the scientific output. The trend was established over the four study period. This informs the vigor and the health of the crop from the greenness of the crop and the biomass. NDVI= (NIR-RED) $/($ NIR+RED) NIR= DN values from Near Infrared band.

able 2. Showing the NDVI analyses

\begin{tabular}{|c|c|c|c|}
\hline COVER TYPE & RED & NIR & NDVI \\
\hline Dense vegetation & 0.1 & 0.5 & 0.7 \\
\hline Dry Bare soil & 0.269 & 0.283 & 0.025 \\
\hline Clouds & 0.227 & 0.228 & 0.002 \\
\hline Snow and ice & 0.375 & 0.342 & -0.046 \\
\hline Water & 0.022 & 0.013 & -0.257 \\
\hline
\end{tabular}

Table above shows typical reflectance values in the red and infrared channels, and the NDVI for typical cover types. Water typically has an NDVI value less than 0 , bare soils between 0 and 0.1 and vegetation over 0.1 . In the study Area crops have an NDVI at the range of 0.4 to 0.5 .

\subsection{Rainfall Data Analysis and Trends Analysis}

Rainfall Trends and Average analysis of the study area was established for the period covered by the study (2015, 2010, 2005 and 2000). Geo Clim which is designed for the analysis of Climatology historical data of rainfall and temperature. CHIRPS_PPT_AFRICA_MONTHLY was downloaded directly from the Geo Clim Links. The data was downloaded for the years needed. The area of Interest was imported to the one of the output files. The data comes inform of .bil, .hdr, .slp. The Extract Grid Statistics dialogue box gives out options on how to run the trend and output the csv files used in further analysis in Microsoft Excel. In the Climatological Analysis of the Climate variables, the rainfall estimates are fished and extracted as a single point for each month as desired, months on analysis and years are analyzed in specific parameters e.g. Average, Trends, Percentiles etc. Plotting of the averages generated as one point per month for the years of study was done using the generated csv files in Excel.

\subsection{Food Production Analysis}

To get the average Production in tones for the area of study for the period established, data was sort and collated from Harvest Choice, Kenya Bureau of Statistics and Fews net East Africa. The data that was not in spatial form was Resampled using Arc Gis to develop a very good Csv table ready for use and tabulation analysis.

Layers of the targeted crops (Maize and Beans) was extracted and used for the analysis. Clipped to the study area. The data is resampled and then Reclassified to generate the desired classes of comparisons. This being year 2000, 2005, 20210 and 2014. It is then exported as a dbf statistical table from Arc Gis to a readable format in Microsoft Excel, Imported to the latter for the final analysis.

\subsection{Conceptual Framework}

Figure 3 shows the procedures that were carried out for every analysis done. The Software used for the analysis and interpretation include; ArcGIS, Envi, Random Forest R, Microsoft Excel.

\section{Results and Discussion}

\subsection{Land Cover Land use Classification}

Land use Land cover classification was done to particularly show and delineate the extents of the farms and cropped areas. The areas of High agricultural production have high concentration of farm lands and cropped areas. Most of the area is under small scale farming. The average farm size is one acre for small-scale farmers and 4 hectares for large-scale farmers. This is due to high population density though the farms are intensively utilized. The areas of Kimahuri, Watuka, Endarasha and Mweiga are the high Agricultural 
producers of the Kieni Sub County area. Dependent on Rain fed farming with occasional irrigation to sustain the crops before onsets of the rains. The area of Karicheni, Solio and upper Kieni West have significantly dominated by grass and shrubs with not so many farming activity. The study was informed that the main crops grown here area Maize, Beans and Irish Potatoes. In the present years, the area has started shifting to Horticultural Framing of Cut flowers, Snow peas, French beans, Cabbages and
Carrots especially areas around Kieni East. From the Data analysis it is clear that there is a decline in cropped areas in terms of hectare rage / Acre rage meaning the Agricultural Food Production has suffered a decline trend.

The study is also informed that the area has witnessed a lot of land use change. From the convectional farming of Potatoes, Beans, Maize to the newly established horticulture farming of cut flowers, French beans and peas, Carrots and vegetables.

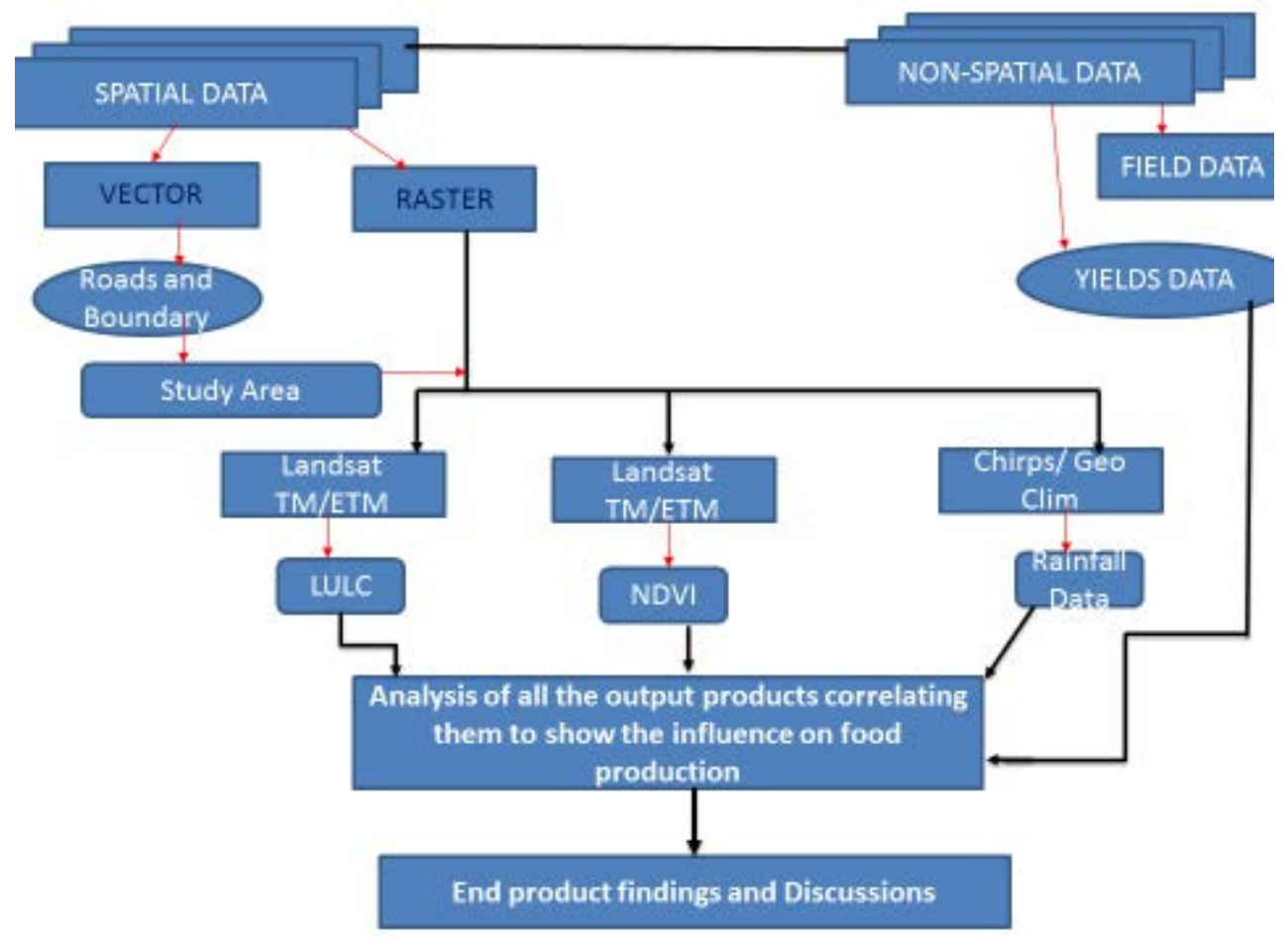

Figure 3. Showing the data processing flow diagram

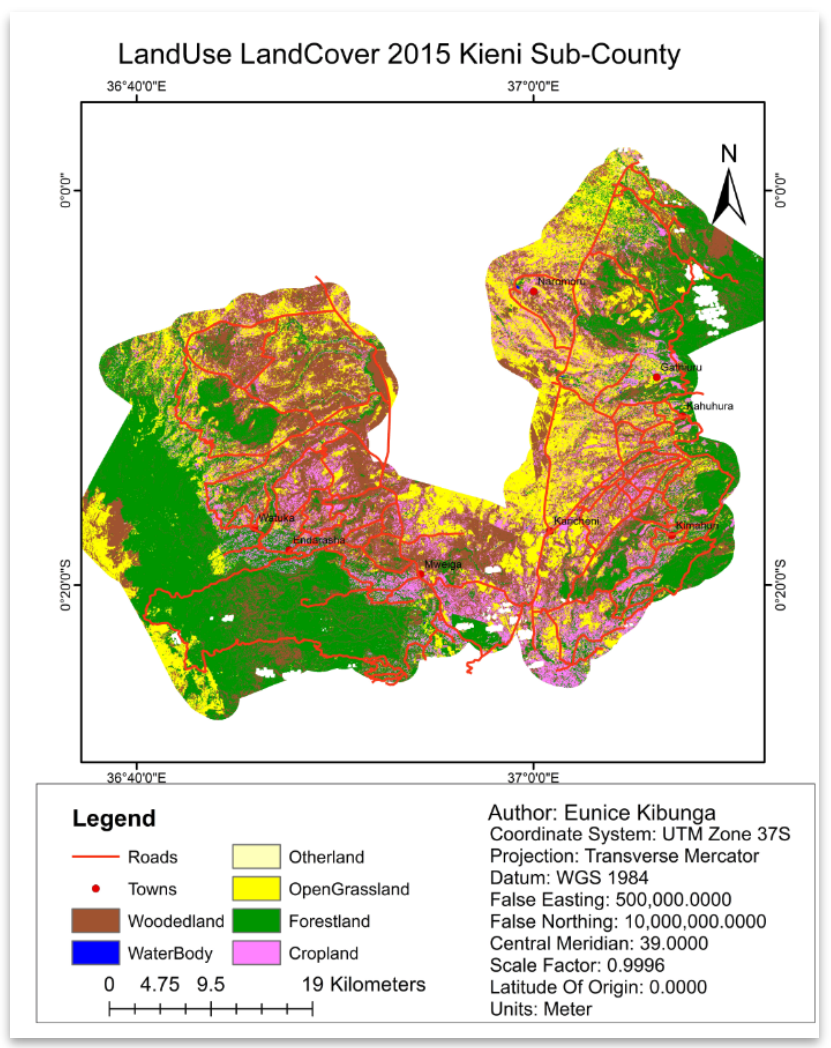

Figure 4(a). Land cover classifications for the year 2015

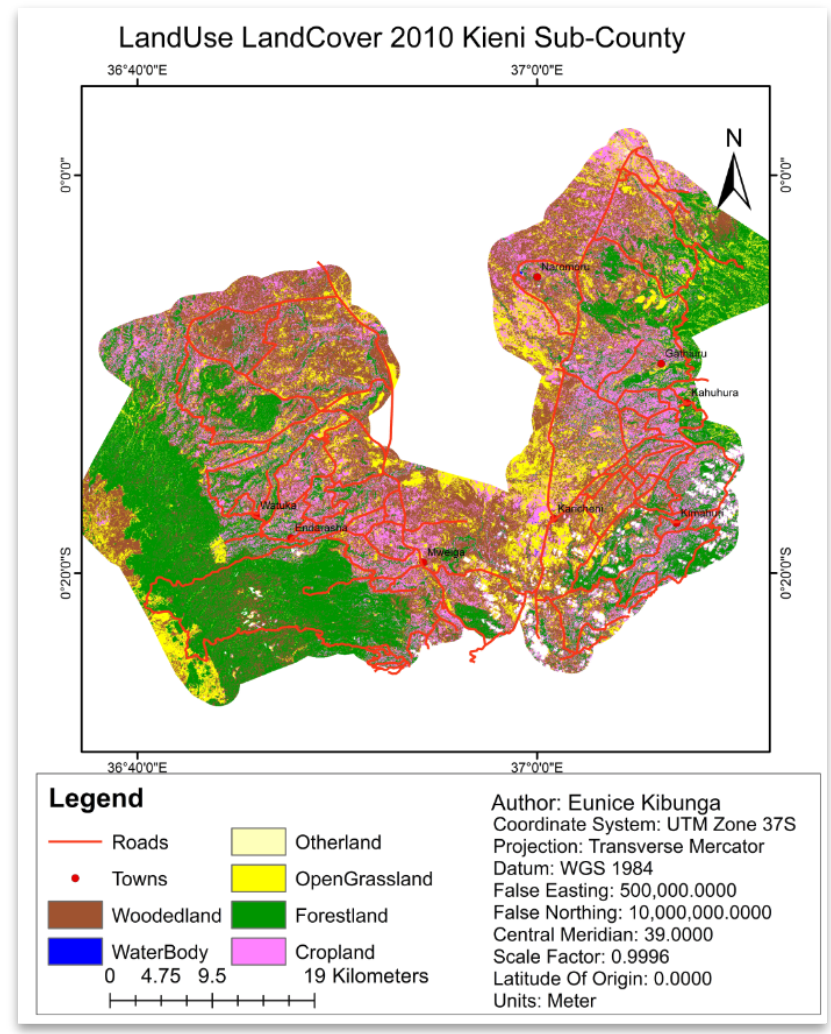

Figure 4(b). Land cover classifications for the year 2010 


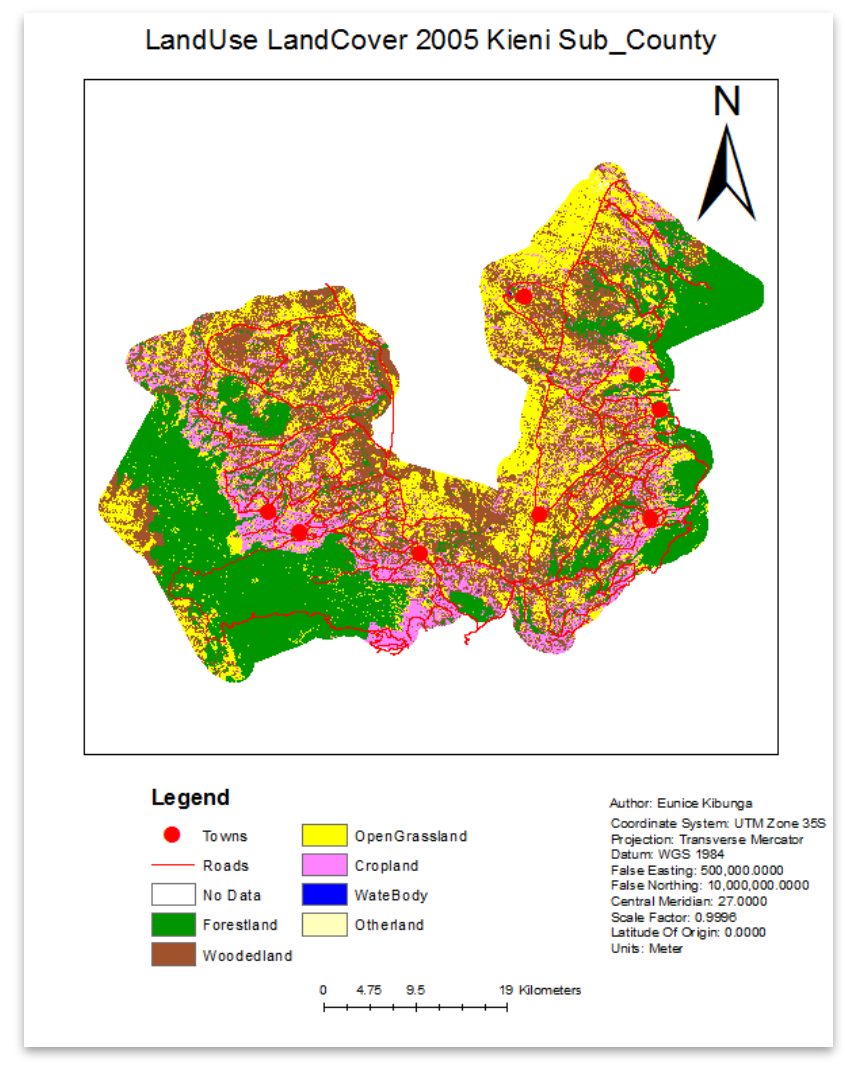

Figure 4(c). Land cover classifications for the year 2005

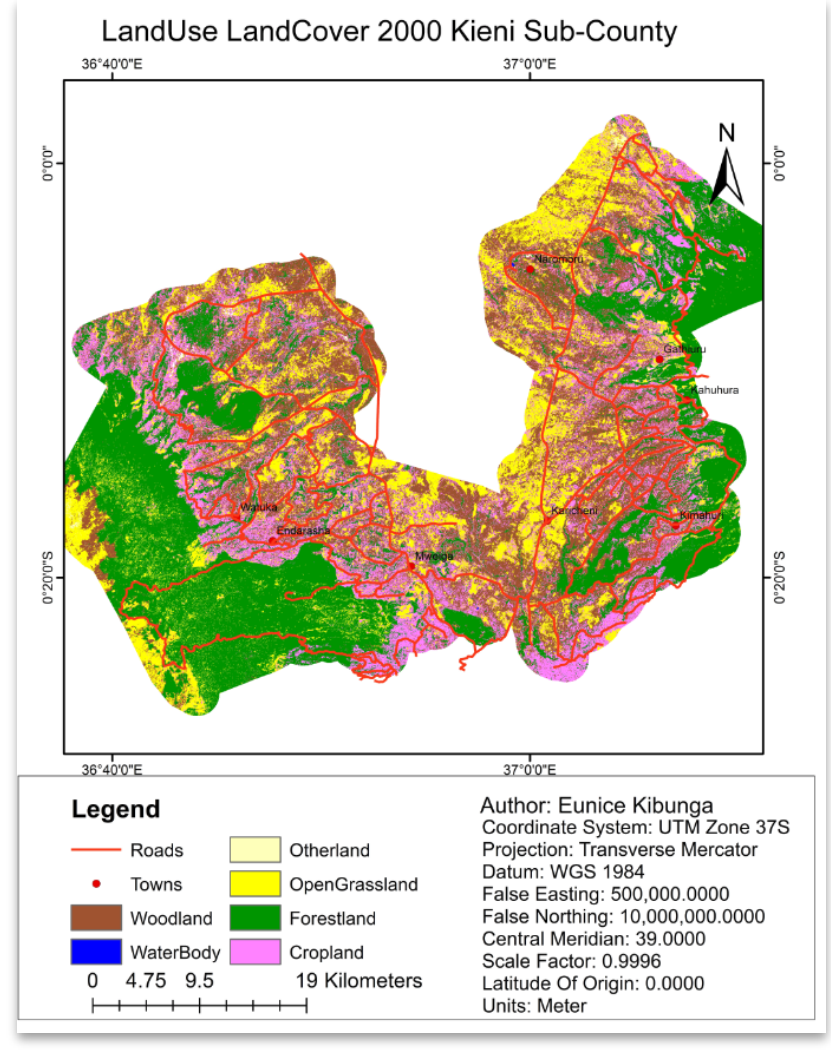

Figure 4(d). Land cover classifications for the year 2000

Table 3.The area in Ha per land use and cover

\begin{tabular}{|c|c|c|c|c|}
\hline & Area_Ha 2015 & Area_Ha 2010 & Area_Ha 2005 & Area_Ha 2000 \\
\hline Forestland & 65147.45 & 61380.54 & 53623.8 & 65792.97 \\
\hline Woodedland & 58520.18 & 57954.24 & 30116.79 & 49005.09 \\
\hline Open Grassland & 40136.80 & 27825.12 & 29824.74 & 36118.98 \\
\hline Cropland & 26641.16 & 42388.29 & 36104.94 & 41514.03 \\
\hline Water Body & 33.40 & 95.49 & 21.06 & 26.46 \\
\hline Otherland & 393.40 & 177.84 & 456.75 & 635.4 \\
\hline
\end{tabular}

\section{Landcover Landuse Statistic trend analysis}
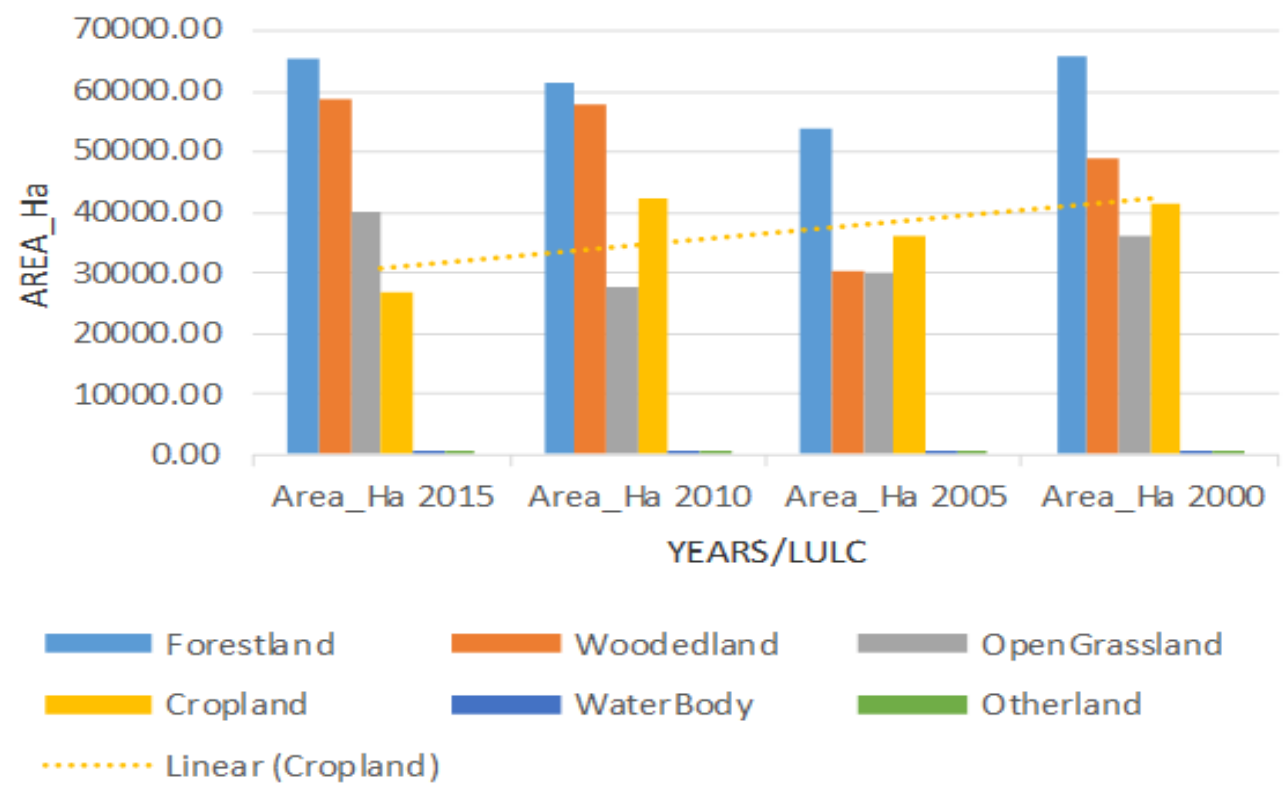

Figure 5 (a). Land cover land user statistics 


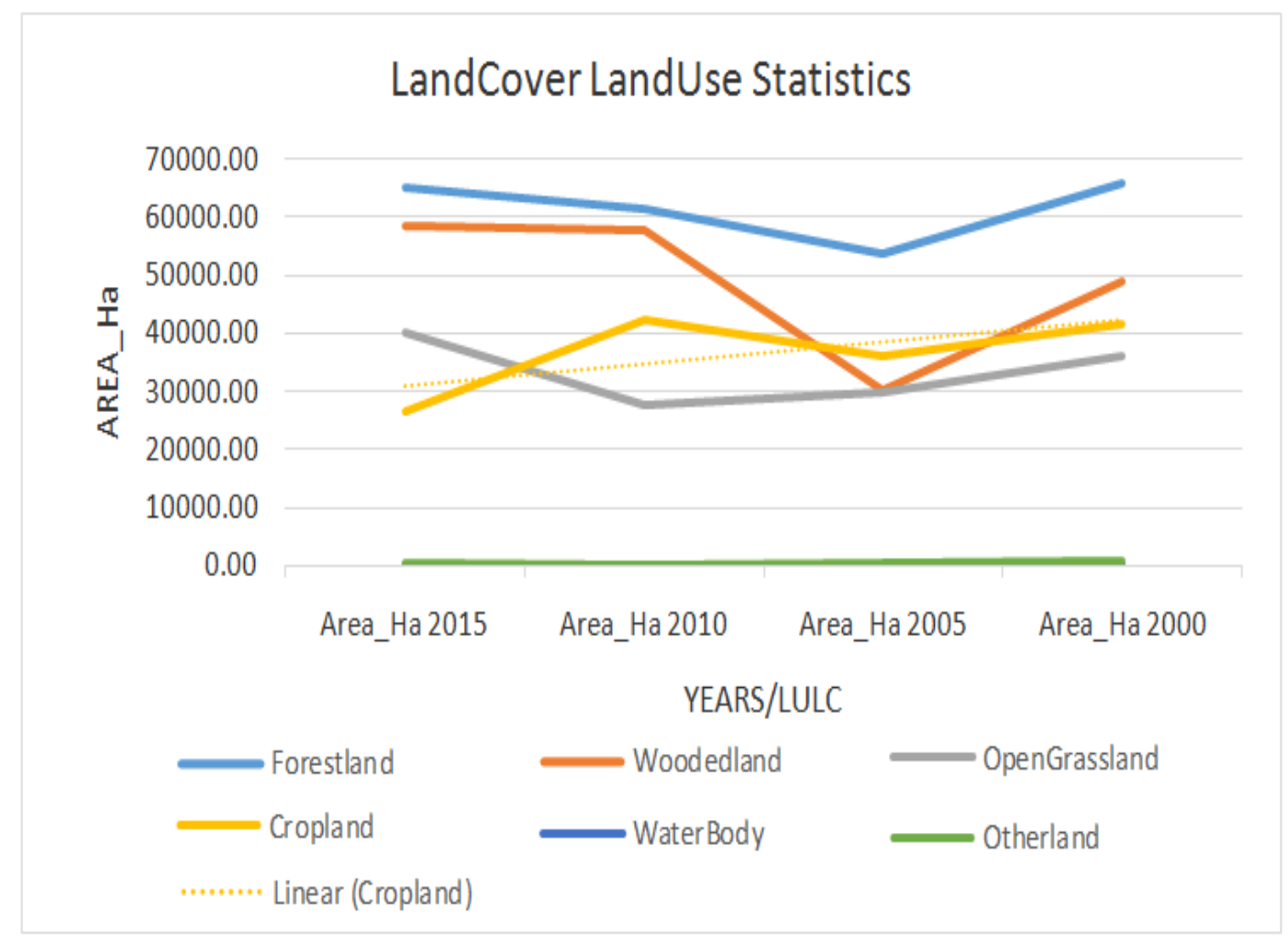

Figure 5 (b). Land cover land user statistics

According to Table 3, the areas under crop/farmed areas tend to have decreased significantly in the year 2015, most of areas converted to Grassland.

The Figure 4 a-d below shows maps of the classified area of study depicting the several land use and land cover types of the area over the period of study.

The bar graphs in Figure 5 a and Figure 5b represents the Land use land cover statistics and trend analysis derived from the classification.

\subsection{Plant Health Vigor and Health (NDVI)}

NDVI derived from Landsat Images was used to monitor the trend of biomass health and vigor. This is very useful to monitor and view crop health variability over the study time, establish the status of the crop (healthy or poor) especially near harvest time. This is important because the farmers and agricultural officers and advisers are able to make timely decisions and if there is a problem are able to respond to it on time.

$$
\text { NDVI }=(\text { NIR }- \text { RED }) /(\text { NIR }+ \text { RED }) .
$$

From the NDVI maps generated, the crop areas have NDVI values of between $0.5 \ldots$ and $0.4 \ldots$ which suggests a health crop.

In 2015, there seems to be a high distribution of poor NDVI near maturity and harvest time which translates to low crop harvest. It also indicates a predominant shrub and grass vegetation compared to the other years. The most grown crops in Kieni Sub County are Maize, beans and potatoes.

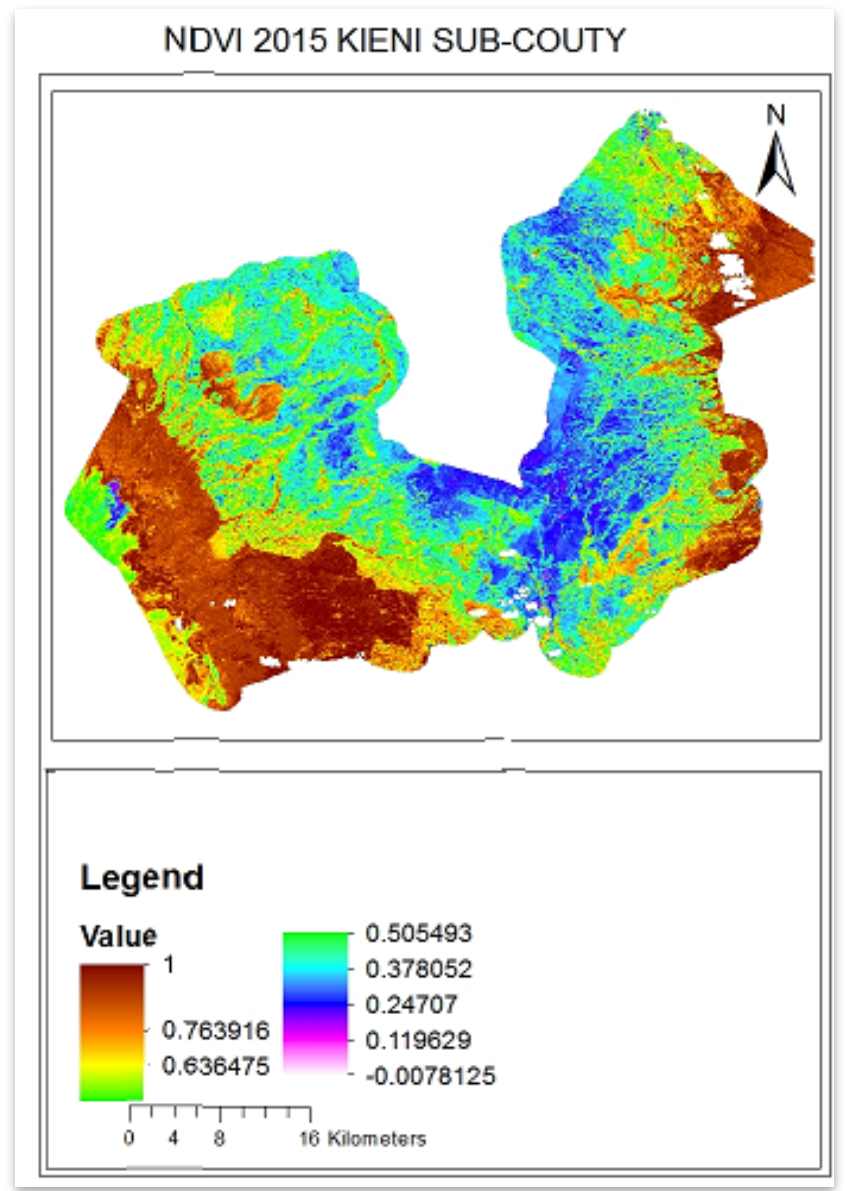

Figure 6 (a). NDVI for the year 2015 


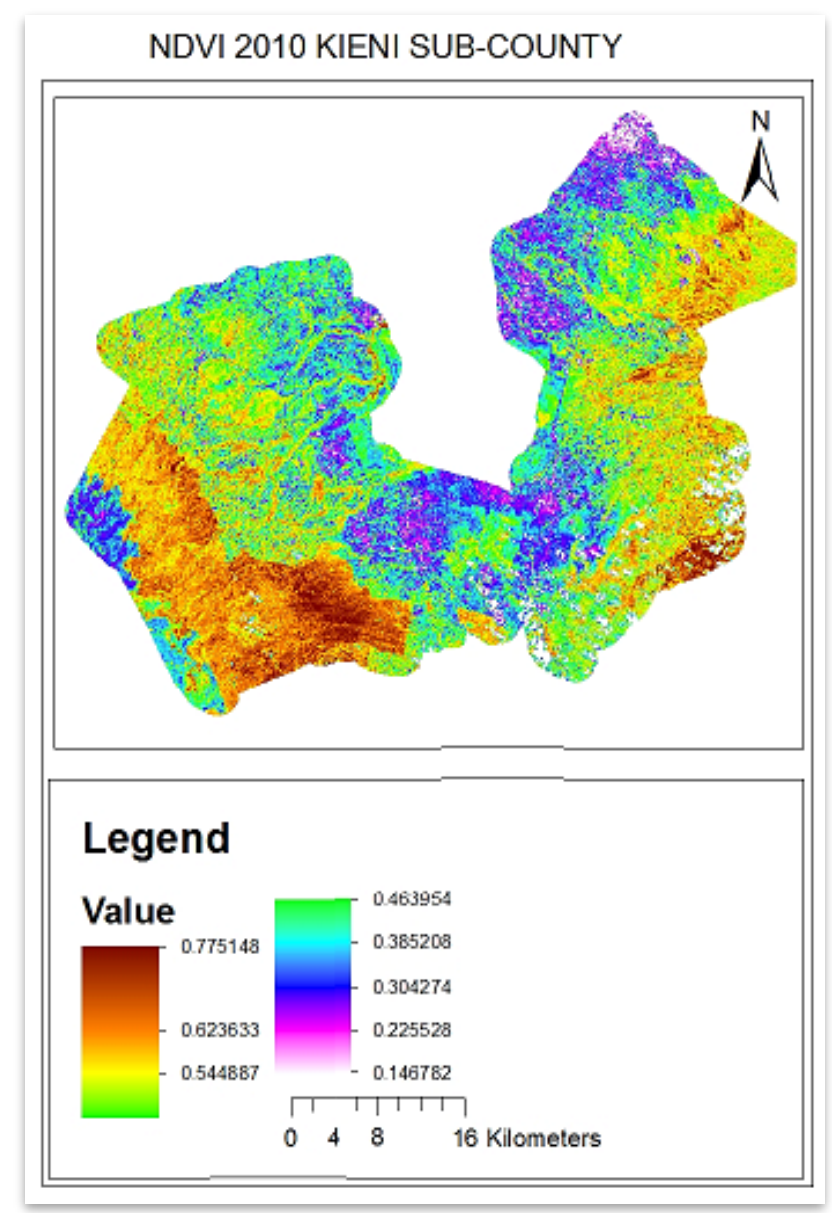

Figure 6 (b). NDVI for the year 2010

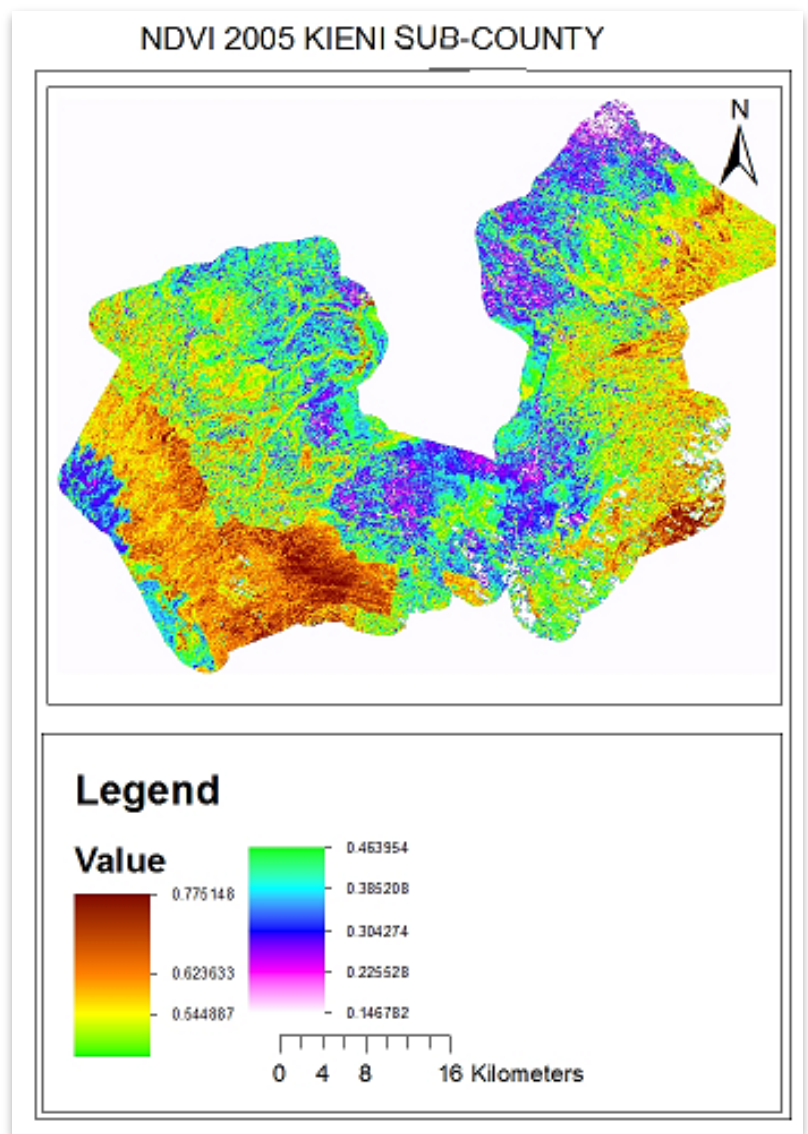

Fig ure 6 (c). NDVI for the year 2005

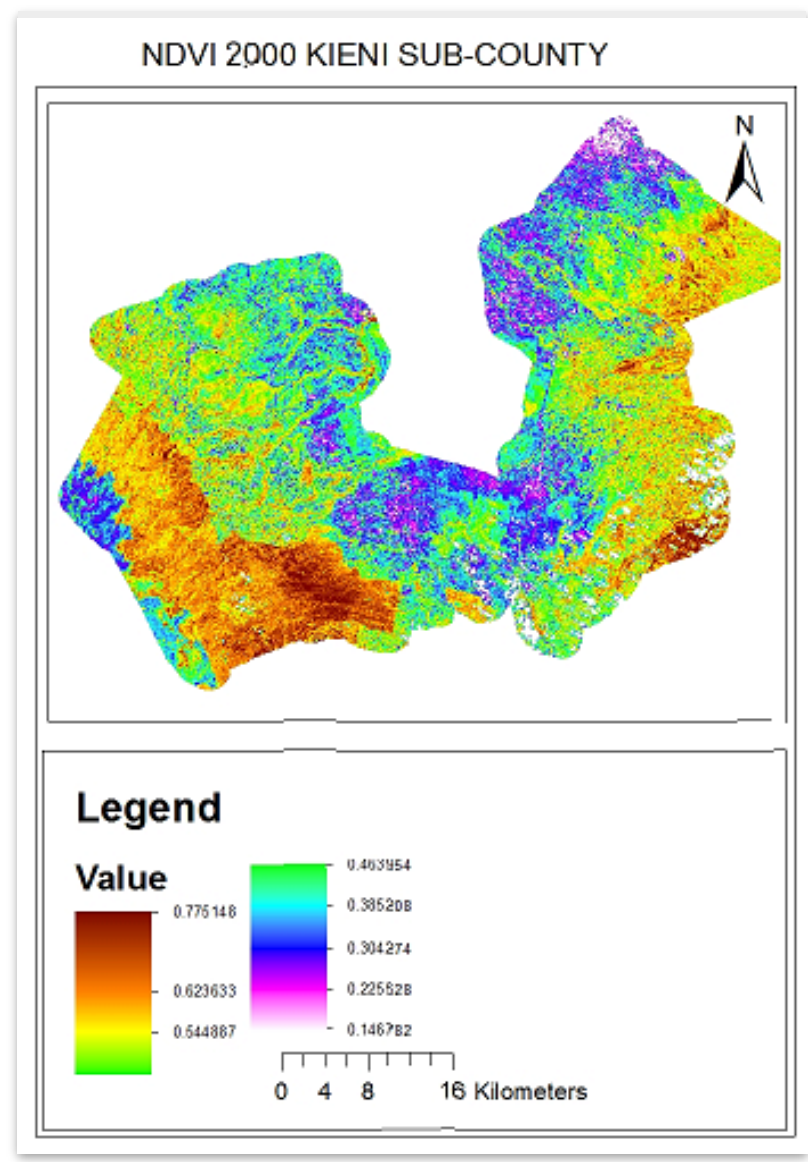

Figure 6 (d). NDVI for the year 2000

\subsection{Food Production on Selected Study Food Crops}

The Data was from http://harvestchoice.org/ and http://www.fews.net/east-africa/kenya analyses on done Microsoft excel. The data was intensively analyzed on a GIS environment. The food products considered in the project were Maize and Beans. The production curve established that there is notable decline and unstable production lines for maize and beans. Maize production was obviously higher than the Beans owing to the fact that the farming of maize was on a higher scale than the Beans. This can be attributed to so many factors and predisposing determinants. Looking at the findings on the Reduced farming lands in the study area, this could consequently lead to are reduction on the area per square of planted Maize and Beans, Failing of crops due to Climatic factors like Rain could also be a factor in the lower production levels of the Study Crops.

Due to over utilization of the land and exhaustion the production per single crop head could have reduced in volume consequently reducing the as the study stretches over the area.

In year 2000 the production the two Crops was highest compared to the other years refer to Figure 8 a and Figure $8 b$. This could be attributed to the larger areas on crop production, better organic soils not so much polluted and diluted by the inorganic chemicals and fertilizers being utilized nowadays and conducive climatic conditions for farming.

In the recent of years, the Kieni area has seen a lot of dynamics in terms of Crop production, conversion of 
farmlands to hoist horticultural growing of cut flowers, French beans, carrots and vegetables has indeed lead to the decrease in the original products of the area namely Maize, Pulses/Beans etc. Where the former earns better dues or the farmer in a shorter period hence the lucrativeness in the Horticulture business.

\subsubsection{Horticulture Farms in Kieni}

In the recent years, many farmers have converted their previously food crop land to the current many horticultural farms. This has brought the food supply and production in this area on its knees.

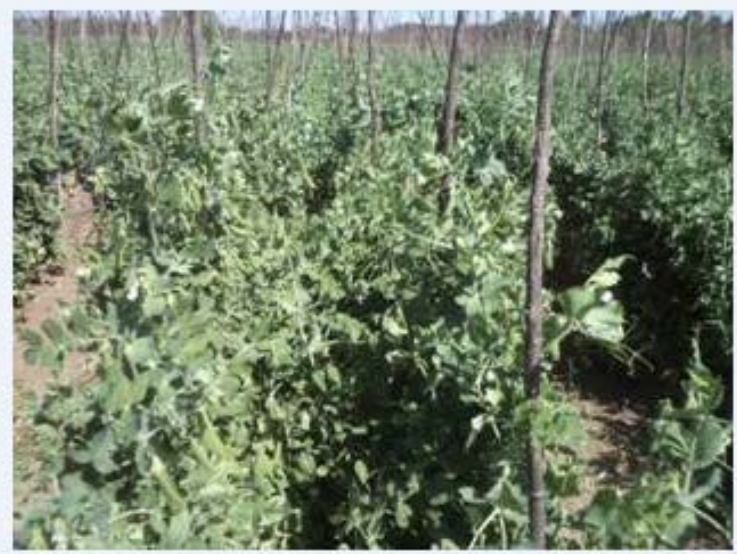

Figure 7 (a). Sugar snaps grown in Kieni replacing food crops

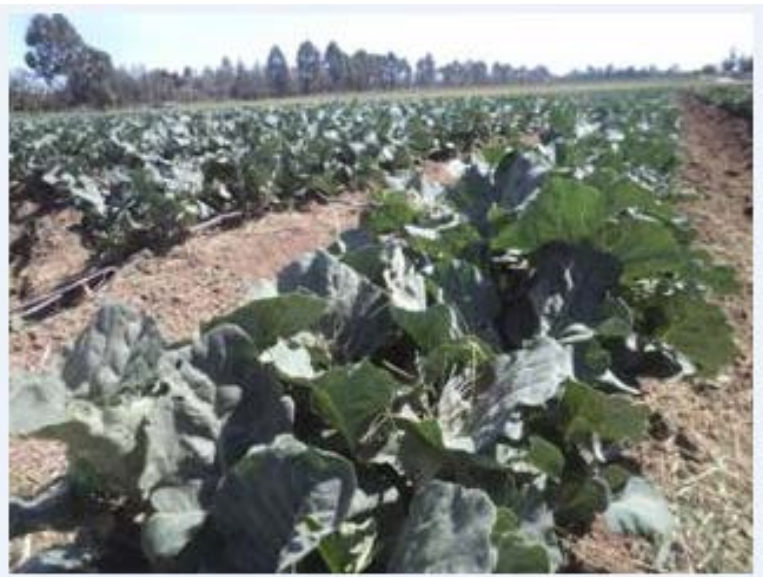

Figure 7 (b). Tender stem Broccoli grown in Kieni replacing food crops

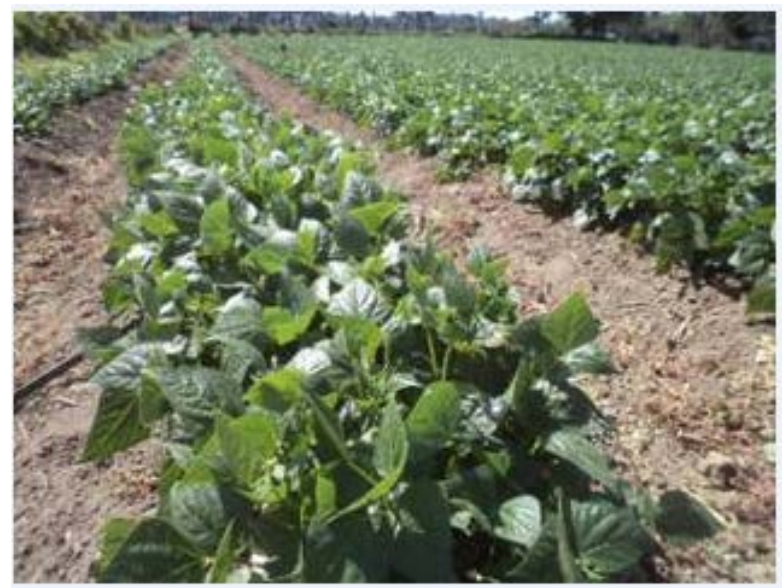

Figure 7 (c). Fine French Beans grown in Kieni replacing food crops

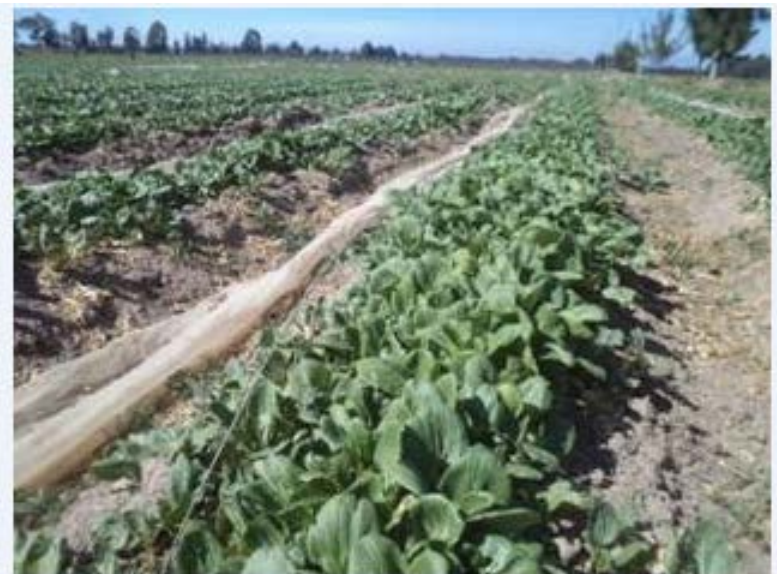

Figure 7 (d). Pak choi grown in Kieni replacing food crops

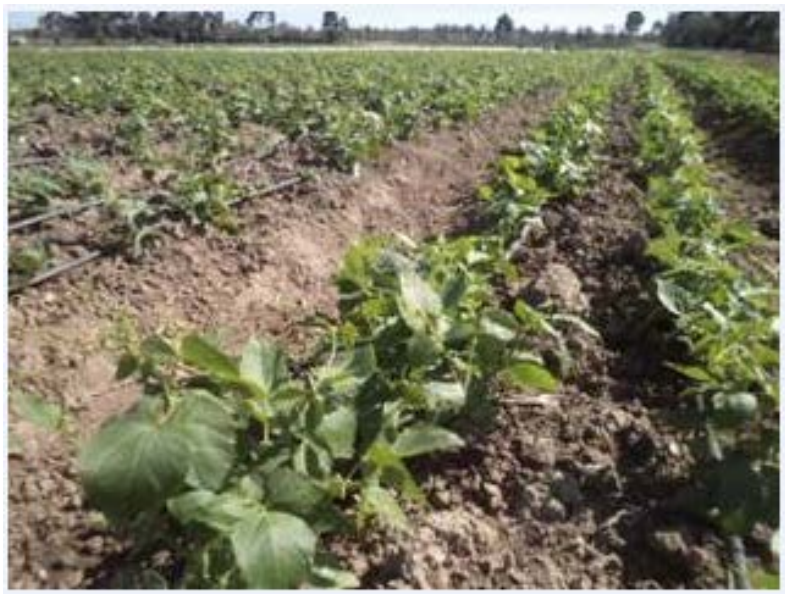

Figure 7 (e). Runner beans grown in Kieni

Above are sample farms taken around Kimahuri and Narumoru areas of already converted large tracts of land from the original food production to horticultural farming of different horticultural products.

\subsubsection{The results on Analysis on the Selected Study Food Crops}

The selected crops are maize and beans being the most cropped/produced in this area and the main staple food for the Kieni residents. The production was considered in metric tons.

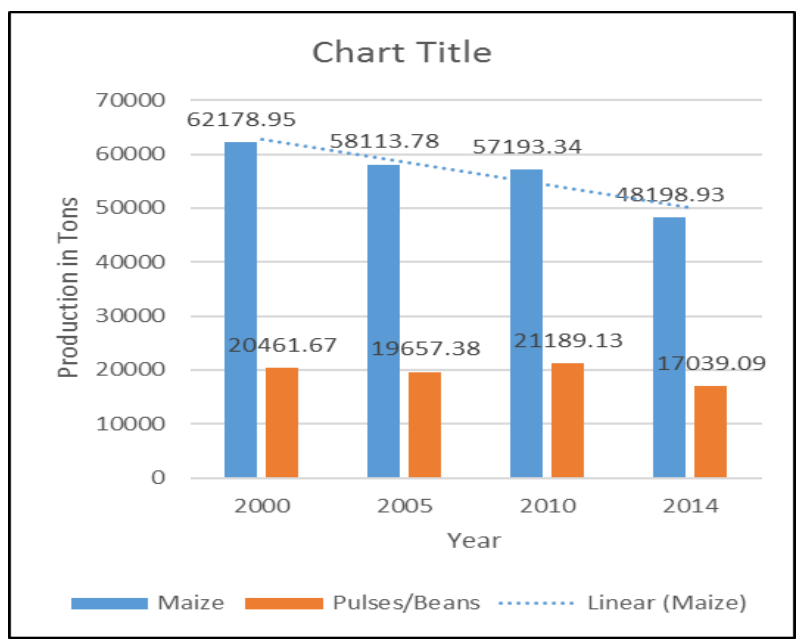

Figure 8 (a). Production curve for maize and beans 


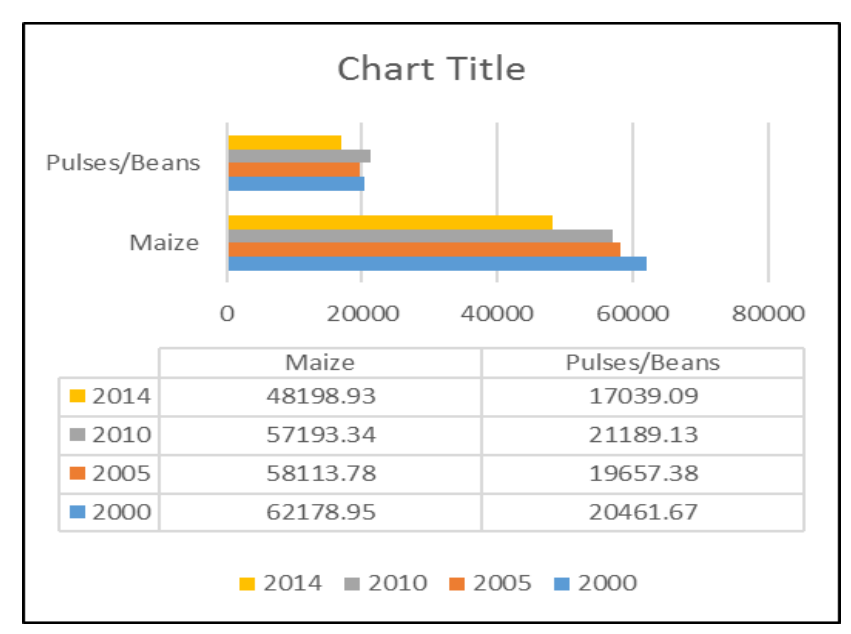

Figure 8 (b). Production curve for maize and beans

\subsection{Rainfall Data Analysis and Trends Analysis}

\subsubsection{Rainfall Trend Analysis}

This part of analysis for the study was very important to actually correlate the declining food production in Kieni Sub County. The analysis on the Chirps data on Rainfall for years 200, 2005. 2010 and 2015 established that during the months of April through May and October through December that's when the area receives its high rainfalls.

In the year 2015, the area received very high amounts of rainfall in the months of April, October and November to the highs of $269.21 \mathrm{~mm}, 154.42 \mathrm{~mm}$ and $190.11 \mathrm{~mm}$ which actually could lead to floods in the farms and affect the croplands destroying the crops/farms which can be one of the causal factors in the low food harvest in that year. Too much rainfall is not suitable for the crops especially grains because it tends to make them rot or not dry as required and for maize can actually accelerate the occurrence if aflatoxins.

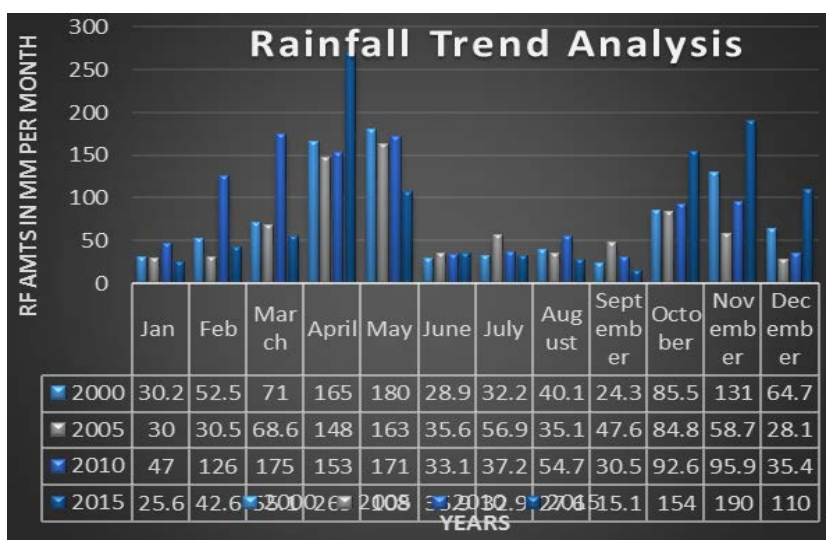

Figure 9. Showing Rainfall Trend Analysis

\subsubsection{Annual Precipitation Analysis}

In the precipitation analysis on Annual ppt from January to December on the years 2015, 2010, 2005 and 2000. In year 2015 the areas of Kabaru location bordering the Mount Kenya forest area experienced the highest of the rainfall to amounts of about $1395 \mathrm{~mm}$ which is very wet. This could actually have been one of the contributors to low food production registered during that year. The years 2005 and 2000 was a good year in rainfall amounts not too much not limited but within the ranges good for cropping between $450 \mathrm{~mm}$ to $700 \mathrm{~mm}$.
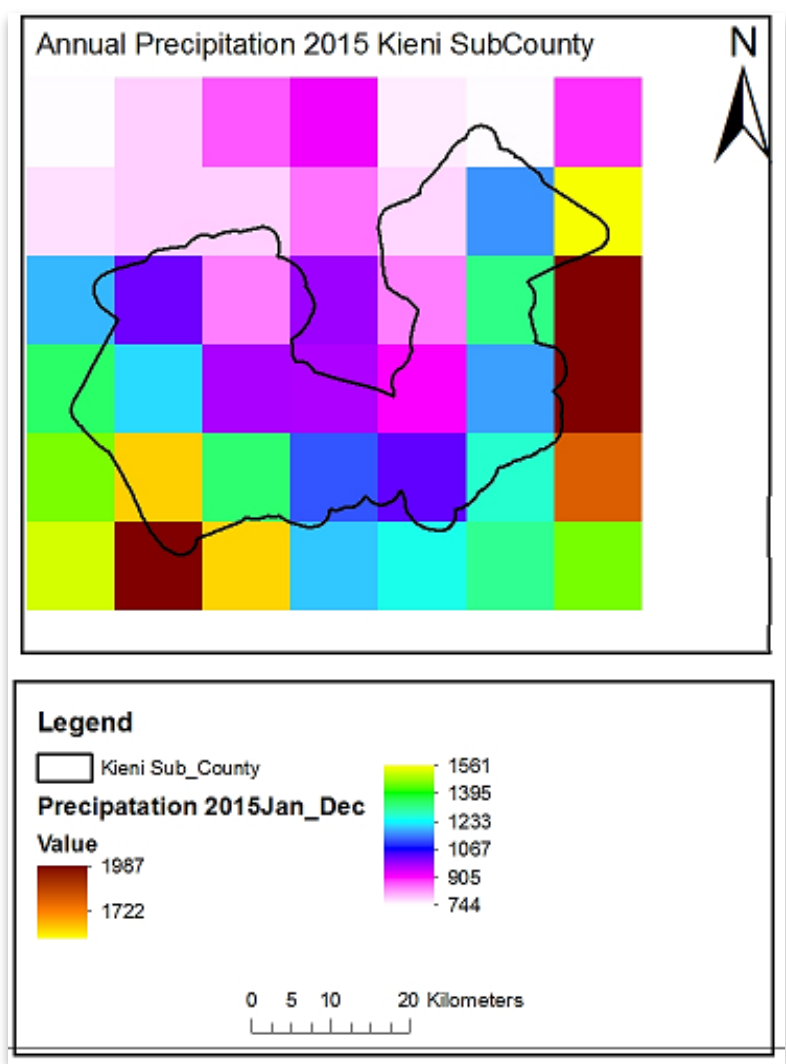

Figure 10 (a). Annual precipitation distribution 2015
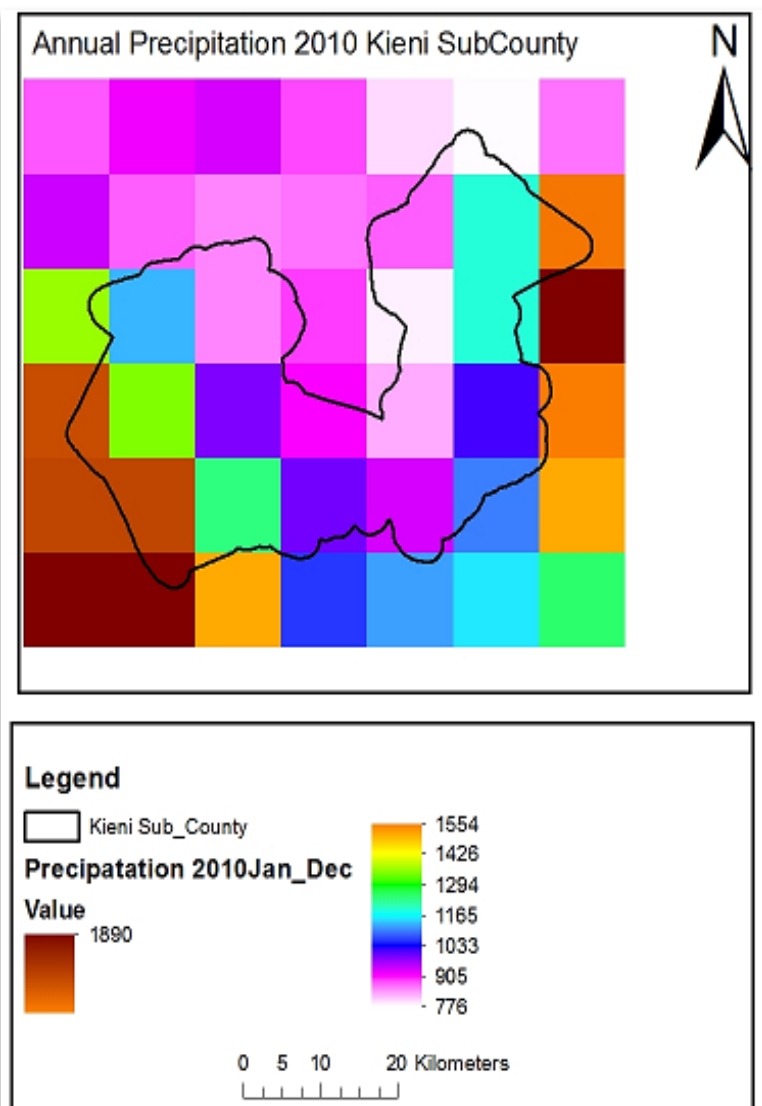

Figure 10 (b). Annual precipitation distribution 2010 

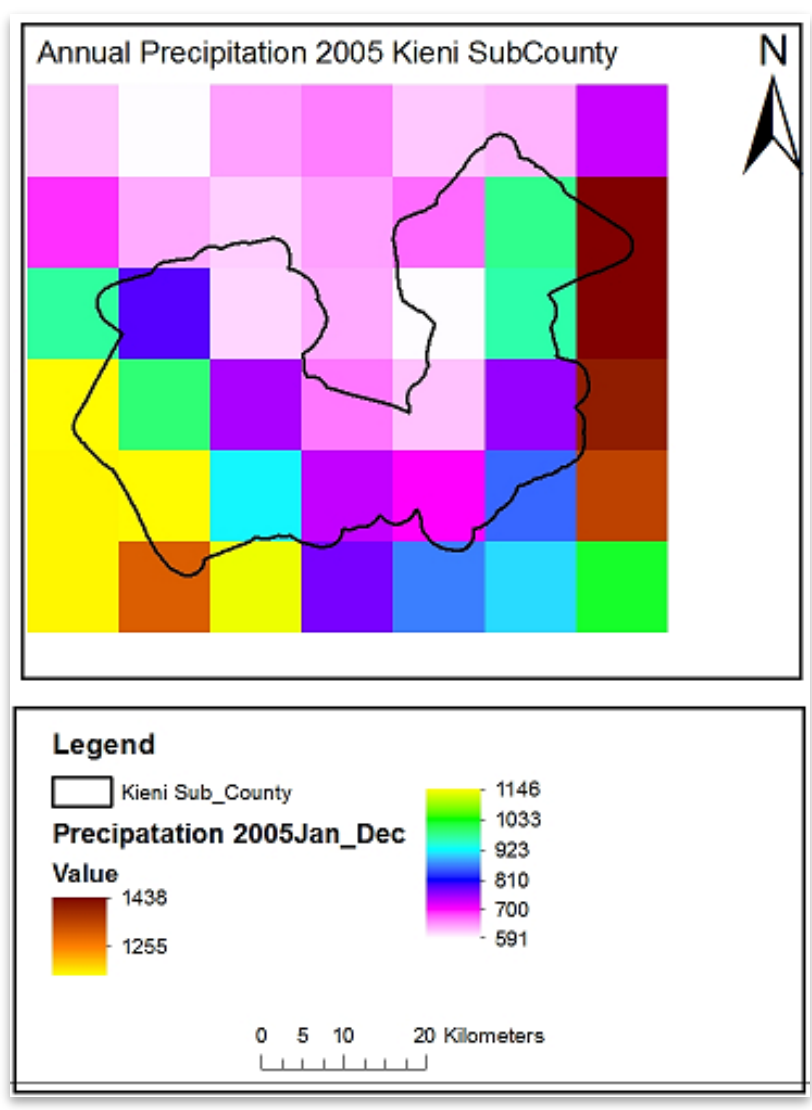

Figure 10 (c). Annual precipitation distribution 2005
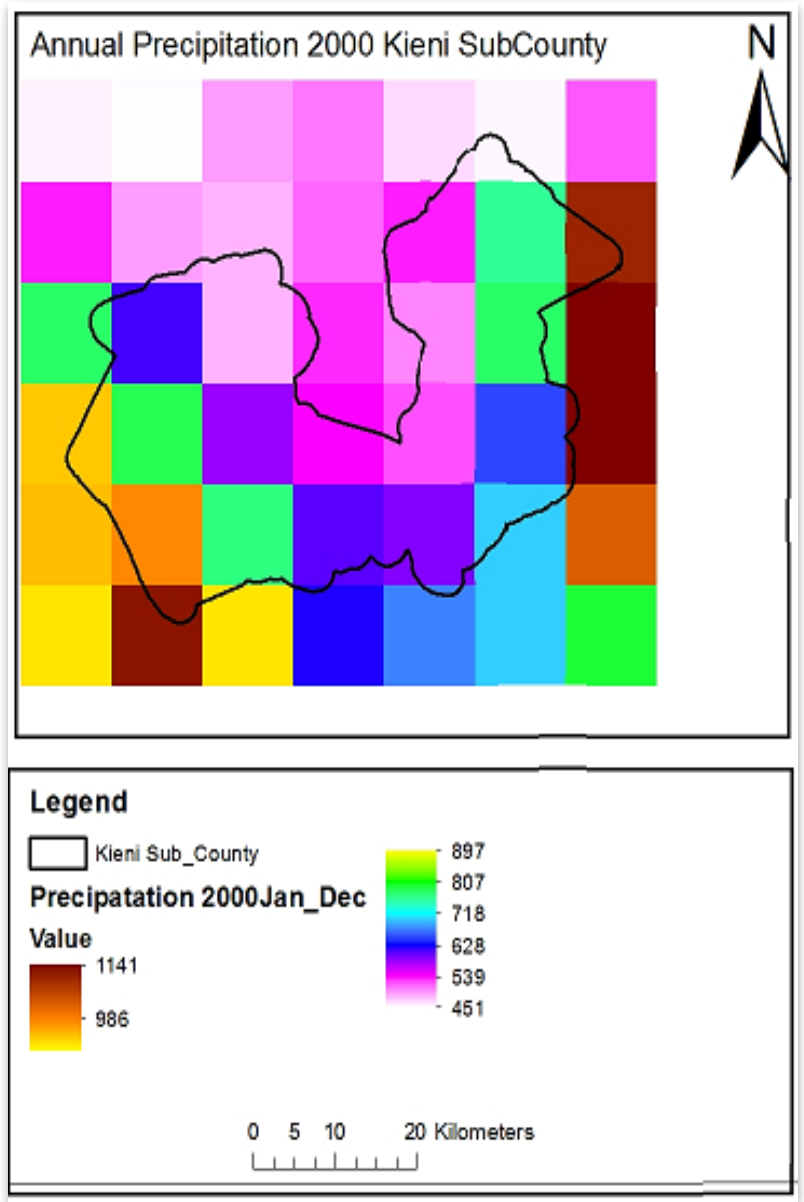

Figure 10 (d). Annual precipitation distribution 2000

\section{Conclusion}

This study carried put in Kieni Sub County clearly depicts the rising cooncerning trend of lowering food produxction status caused by several factors but not limite to the once in the study. This is an alarming state of matter that should acually attract the decision makers in this sector to avert and stop the worrying trend. An area that was previously self sufficient and could actully feed itself and sell the abadunt harvest now relying on having to struggle in food security is areason enough for the stakeholders to address the issues.

Monitoring of the land use land cover extents and assess the conversionds from one use to another is very essential because it informs the trends and knows where gaps are established as aresult of he said conversions.

Monitoring of the NDVI (Crop vigor) is equally important since the trend can be anayzed to observe when periods of dryness or drought stress to the crops occurred in the growing period season of the crops. This could be caused by moisture content reduction in the soil which is bassically low rainfall in te area.

The study establishes the dynamic changes in rainfall and precipitation in the area. This has a significant effect on the production since most of the agricultural activities here are non mechanised rainfed agriculture. With the changing dynamics with rainfall trends, onsets and occurences, this a great negative effect too to the cropping system and production of the area.

This study reccommends that as the farmers are shifting to horticulture farming and abandoning food cropping, then then a good intergration and balance should be established to meet the demands in food security as well as the economic benefit of the horticutural industry. To also intergrate rainfed agriculture with irrigated agriculture to avert the damages that are caused by failed raibns or too much of it that lowers production as well as increase crop yiled since farmers can caputalise and maximise on farming throught out the year, this will ultimately improve food security.

The reserch still needs furthwer intergrations and studies to effectively conclude on the causes of the declinig food production and come up with sustainable ways to avert and address the situation.

\section{References}

[1] Matarira, C. H.; Makadho, J. M.; Mwamuka, F. C. 1995. "Zimbabwe: Climate Change Impacts on Maize Production and Adaptive Measures for the Agricultural Sector" in Ramos-Mane, C. and Benioff, R. (Editors) Interim Report on Climate Change Country Studies, US Country Studies Program, Washington, DC.

[2] Hansen, J. W.; Baethgen, W.; Osgood, D.; Ceccato, P.; Ngugi, R. K. 2007. 'Innovations in Climate Risk Management: Protecting and Building Rural Livelihoods in a Variable and Changing Climate' SAT eJournal, Vol. 4, Issue 1. ejournal.icrisat.org.

[3] FAO,2000, Agricultural Development and Related Aspects in the horn of Africa, ACC inter-Agency Task Force on the UN Response to Longer Term Food Security.

[4] Buckland, R. W. 1997. "Implications of Climatic Variability for Food Security in the Southern African Development Community." Internet Journal of African Studies, Issue No.2 - March; Using Science against Famine: Food Security, Famine Early Warning, and El Niño 
[5] FAO, 2008, Climate change and food security: A framework Document Rome.

[6] Agriculture Livestock Sector Working Group of the Kenya Food Security Steering Group (KFSSG). 2011. Crop, livestock and fisherioes high rainfall areas Assessment , FAO and GOK.

[7] Adaptation to Climate Change for Smallholder Agriculture in Kenya. Inception Report, April 2009. IFPRI. Ringler, C., et al. 2009.

[8] Suri, T., Tscherley, D., Irungu, C., Gitau, R. And Kariuki, D., 2008. Rural Income, Inequality and Poverty dynamics in Kenya. Tegemeo Institute of Agricultural Policy and Development WPS/30/2008

[9] Sen, A. 1981. Poverty and Famines.Oxford: Clarendon Press. SID GOK and SIDA, 2004. Pulling Apart: Facts and Figures on Equality in Kenya.

[10] Republic of Kenya, 2011. National Food and Nutrition Security Policy. Agricultural Sector Coordination Unit (ASCU, Kilimo House, Cathedral Road, Nairobi, Kenya.
[11] Mosher, A.T., "In Leagans, P., \& Loomit, C. Agricultural Development: Behavioural Change in Agriculture”, Cornell University Press. 1971.

[12] Kiome, R., "Food Security in Kenya, Ministry of Agriculture", Republic of Kenya. 2009.

[13] Republic of Kenya, 2008. The impact of rising food Prices on disparate livelihood groups in Kenya. The Kenya Food Security Steering Group (KFSSG), Nairobi, Kenya.

[14] Republic of Kenya, 2010. The 2009 Kenya Population and Housing census Volume 1 A. Population Distribution by Administrative Units. KNBS.

[15] Kimenye, L. (1995). Kenya's Experience Promoting Smallholder Production of Flowersand vegetables for European markets. African Rural and Urban Studies.

[16] Jaffee, S. (1995). The Many Faces of Success: The Development of Kenyan Horticultural. Washington DC: The World Bank.

[17] FAO. (2002). Food and Agriculture Organization of the United Nations: The State of Food Insecurity in the World 2002. Rome. 